Appl. Anim. Behav. Sci. 144, pp. 136-146. (doi:10.1016/j.applanim.2013.01.00)

\title{
Sleeping tight or hiding in fright? The welfare implications of different subtypes of inactivity in mink
}

Rebecca K. Meagher ${ }^{1}$, Dana L.M. Campbell ${ }^{1}$, Jamie Ahloy Dallaire ${ }^{1}$, María Díez-León ${ }^{1}$, Rupert Palme $^{2}$, Georgia J. Mason ${ }^{1}$

${ }^{1}$ Animal and Poultry Science Department, University of Guelph

50 Stone Road East, Building \#70

Guelph, Ontario, Canada N1G 2W1

${ }^{2}$ Department of Biomedical Sciences/Biochemistry, University of Veterinary Medicine

Veterinärplatz 1

A-1210, Vienna, Austria

*Corresponding author

rkmeagher@gmail.com

Telephone: $+1-519-824-4120$ ext. 53557

Fax: +1-519-836-9873 


\begin{abstract}
Effects of sub-optimal housing on inactivity vary across species and experiments, probably because inactivity is heterogeneous, reflecting both positive states (e.g. relaxation) and negative ones (e.g. fear). We therefore aimed to identify specific subtypes of inactivity that could indicate poor welfare in mink, by comparing their behaviour in enriched and non-enriched conditions (the former having been previously demonstrated to be highly preferred by mink and to enhance their welfare). We assessed this in three groups of subjects, as well as after housing conditions were reversed for the last group. During live scans, inactive animals were scored for posture, location, and whether awake or apparently asleep. Data on temperament and physiological stress indicators were also collected for one group; these confirmed that non-enriched housing increased faecal cortisol metabolites (FCM; $\mathrm{P}=0.040)$. Non-enriched housing also increased locomotor stereotypy in females (sex*housing: $\mathrm{P}=0.004$ ). Inactivity in the nest-box (vs. in the open cage) was higher among females in non-enriched housing (housing*sex $\mathrm{P}<0.001$ ), and increased by $20 \%$ of observations after enrichment removal $(\mathrm{P}=0.018)$ for both sexes. Furthermore, males with fearful temperaments spent the most time inactive in the nest-box (sex*temperament $\mathrm{P}=0.054$ ), while females whose FCM decreased most when given enrichment also showed the largest decreases in this behaviour (sex*FCM change $\mathrm{P}=0.019$ ). Together, this suggests that inactivity in the nest-box may reflect anxiety-induced hiding. Lying awake (i.e. prone with eyes open) was also higher in non-enriched housing (3.1\% of observations vs. $1.7 \% ; \mathrm{P}=0.002)$; furthermore, this subtype of inactivity increased after enrichment removal (by 1.0\% of observations; $\mathrm{P}=0.021$ ), and decreased when non-enriched mink were given enrichment (by $2.4 \%$ of observations; $\mathrm{P}=0.004$ ). This behaviour did not co-vary with fearfulness, however, nor with FCM (both $\mathrm{P}>0.05$ ). This suggests that lying awake is not fear-related (e.g. not reflecting enhanced vigilance) but instead reflects some other negative state. Effects on inactivity subtypes as defined by posture were less consistent. For example, time spent lying belly down tended to decrease in mink moved from non-enriched to enriched cages $(\mathrm{P}=0.054)$, but enriched mink spent significantly less time belly down (in one of the three groups; $\mathrm{P}=0.002$ ). Overall, two subtypes of inactivity, lying in the nestbox and lying awake seem likely to be valid indicators of housing-induced poor welfare in this species, being consistently increased by non-enriched cages. Lying in the nest-box may indicate fear or anxiety, and lying awake, a boredom-like state.
\end{abstract}

\title{
Keywords
}

American mink, Neovison vison, inactivity, hiding, environmental enrichment, animal welfare

\section{Introduction}

Animals in impoverished environments are sometimes much more inactive than those in enriched ones (e.g. chimpanzees: Baker, 2004; foxes: Koistinen et al., 2009; lemurs: Dishman et al., 2009; parrots: Rozek et al., 2010). This inactivity has been suggested to indicate compromised welfare, for two reasons. First, similar effects sometimes occur in situations known to be aversive; for example, felids spend much time inactive and hidden when exposed to stressors such as 
Appl. Anim. Behav. Sci. 144, pp. 136-146. (doi:10.1016/j.applanim.2013.01.00)

translocation (e.g. Carlstead et al., 1993; Rochlitz et al., 1998; Wielebnowski et al., 2002), as do rodents exposed to predation threat (e.g. Dalm et al., 2009). Second, it has been suggested that high levels of inactivity induce boredom or depression-like states (e.g. Carlstead, 1996; Wemelsfelder, 1990). However, not all welfare improvements correspondingly decrease inactivity levels: environmental enrichments sometimes increase them instead (e.g. rodents: Tilly et al., 2010; Würbel et al., 1998). This lack of consistent overall pattern is almost certainly because inactivity is a broad category of behaviour, including not just forms associated with stress, but also forms associated with relaxation such as sleep and rest. It would therefore be valuable to be able to distinguish forms of inactivity reflecting good welfare from those reflecting poor welfare.

This may be possible phenotypically, based on indicators such as location, whether the animal is asleep or awake/alert, and posture. Location is clearly the key to identifying hiding, which by definition means being concealed. In the studies cited above, for instance, hiding felids remained under shelters or behind objects screening them from human sight (e.g. Carlstead et al., 1993). High alertness may also reflect fear: remaining stationary but alert is often considered a form of vigilance (e.g. Rasa, 1989; Soriano et al., 2006), and thus a sign of fear or anxiety (e.g. Carlstead et al., 1993). Low alertness (e.g. sleep or drowsiness) by contrast, is more likely to reflect relaxation and therefore good welfare (e.g. Abou-Ismail and Mahboub, 2011; Crockett et al., 1995). Finally, many researchers have used posture to identify subtypes of inactivity. Lying postures can vary with level of physical comfort (e.g. on soft mats vs. concrete floors: Tuyttens et al., 2008), and between true sleep and other forms of rest (reviewed by Langford and Cockram, 2010). In some species, such as rats (Tromp et al., 1990) and foxes (Tembrock, 1979), lying curled may indicate deeper sleep or increased motivation to rest than other positions. Several authors also hypothesize that certain postures indicate specific negative affective states such as lethargy or boredom (dog-sitting in sows: Fraser, 1975; Vestergaard, 1984; hunched postures in rabbits: Gunn and Morton, 1995). Finally, lying with the belly exposed is generally considered a vulnerable position (e.g. Petrů et al., 2009) and might therefore indicate relaxation, while lying belly down likely allows the fastest escape if awoken (cf. Aristakesyan, 2009) since it is closest to a standing position.

In mink (Neovison vison), relationships between welfare and overall inactivity levels are equivocal. On an individual level, mink that are very inactive tend to exhibit negligible 
stereotypic behaviour in non-enriched fur farm cages (Axelsson et al., 2009; Bildsøe et al., 1991; Meagher et al., 2012; Svendsen et al., 2007a). Low-stereotyping mink have, in some studies, been found to have the highest levels of glucocorticoids (Bildsøe et al., 1991) and an increased risk of being fearful (Hansen and Jeppesen, 2006). However, such patterns are not always found (see Malmkvist et al., 2011; Meagher et al., 2012; Svendsen et al., 2007b). Turning to population level effects, two studies have investigated effects of environmental enrichment on mink inactivity. One reported no change (Vinke et al., 2005), the other, a decrease (Hansen et al., 2007). Distinguishing between subtypes of inactivity may well be useful in this species. For example, although most resting occurs in the nest-box (which may be a comfortable location), mink also retreat to this structure when moved to a new cage (Mason, 1992), startled (Nimon and Broom, 1999), or anticipating aversive stimuli (Hansen and Jeppesen, 2006). The nest-box may thus be perceived as a refuge (indeed depending on cage design, mink may be harder to see and/or to catch when inside it), and so at least some instances of inactivity in this location could reflect hiding.

The aim of the current experiments was to determine how housing influences inactivity in mink, especially specific subtypes differentiated by apparent alertness or arousal, location and posture. This would allow us to identify forms that could be useful as welfare indicators, assuming that enrichment is associated with improved welfare. Data were collected from three separate groups of mink, over a 4-year period. Our enriched cages were large structures that included enrichments identified by prior studies (e.g. Hansen et al., 2007; Mason et al., 2001) as motivating and stress-reducing for mink. Previous studies from our laboratory confirmed that these cages benefit mink: subjects would push heavily weighted doors to access them (Dallaire et al., 2012), and they reduced stereotypic behaviour, faecal glucocorticoid metabolites, and several other signs of stress in animals raised in them (Díez-León and Mason, 2010; Campbell et al., 2013). Our first set of hypotheses was that non-enriched cages would: 1a) reduce time spent sleeping rather than lying awake; 1b) increase time spent inactive in the nest-box, and decrease inactive time in exposed areas of the cage; and 1c) influence the postures shown while inactive. This posture analysis was largely exploratory, since there are no published studies of mustelids' resting postures; however, we did hypothesize that if non-enriched cages caused fear or anxiety, they would decrease time spent lying with the belly exposed. Second, we hypothesized that these effects of non-enriched housing would be stronger in mink with prior experience of enrichment. 
Appl. Anim. Behav. Sci. 144, pp. 136-146. (doi:10.1016/j.applanim.2013.01.00)

Removing enrichment should decrease welfare more than never experiencing enrichment (e.g. Latham and Mason, 2010), and other studies correspondingly suggest that enrichment loss can induce effects on inactivity that are not seen in individuals never exposed to enrichment (cf. Bolhuis and colleagues [2006], who found pigs moved from enriched to barren pens were the most inactive; and Hansen and colleagues [2007] who found that mink whose access to an extra cage was removed spent more time in the nest-box). Our third hypothesis was that subtypes of inactivity that were elevated in non-enriched cages would be associated with greater fearfulness and chronic stress, as assessed using temperament and baseline glucocorticoid levels.

\section{Material and methods}

\subsection{Housing treatments}

All mink (all Black in colour-type) were individually housed in one of two cage types, enriched (E) or non-enriched (NE). NE cages were $75(\mathrm{~L})$ x $60(\mathrm{~W})$ x $45(\mathrm{H}) \mathrm{cm}$, with a nest-box on the front. E cages consisted of an identical home cage, plus access to a second cage $120 \mathrm{~cm}$ wide via an overhead "tunnel" built of wire mesh (see diagram in Dallaire et al. 2012). This second cage included a trough of running water to allow wading and head-dipping, a plastic "hammock", and many manipulable objects, new ones added monthly. For Groups 1 and 2, there was also an extra nest-box in this cage. They were exposed to a natural light cycle, via artificial lights yoked to sunrise and sunset.

\subsection{Group 1}

The first group were all males, 23 housed in E cages, and 24 in NE cages, beginning in July (aged 3 months). They were observed live over two 5-day periods spanning late December to early February. Seventeen consecutive instantaneous observations of each mink were conducted in each of two 4-min observation periods, between 08:30 and 14:00 h, always before feeding, which occurred late afternoon. The observer quietly stood as far from the cage as possible while being able to discern behaviour. These focal observation periods minimized disturbance to the mink, who would stop watching the observer after approximately $30 \mathrm{~s}$. Observation time was balanced between individuals across days. Behaviour, location, and posture if inactive were recorded according to the ethogram shown in Table 1. 
Appl. Anim. Behav. Sci. 144, pp. 136-146. (doi:10.1016/j.applanim.2013.01.00)

Table 1. Ethogram.

\begin{tabular}{|c|c|}
\hline Category & Description \\
\hline \multicolumn{2}{|c|}{ Behaviour pattern } \\
\hline $\begin{array}{l}\text { Locomotor } \\
\text { stereotypy }\end{array}$ & $\begin{array}{l}\text { Movement or sequence of movements of the whole body or upper body (e.g. } \\
\text { pacing or bobbing) repeated at least three times consecutively }\end{array}$ \\
\hline $\begin{array}{l}\text { Borderline } \\
\text { locomotor } \\
\text { stereotypy }\end{array}$ & $\begin{array}{l}\text { Apparently stereotypic behaviour repeated fewer than three times or } \\
\text { switching between elements of common stereotypies without repeating a } \\
\text { sequence three times }\end{array}$ \\
\hline Scrabbling & Scratching continuously at a wall of the nest-box or cage for $\geq 3 \mathrm{~s}$ \\
\hline \multicolumn{2}{|l|}{ Inactivity } \\
\hline Resting & Lying relatively still with eyes closed or head tucked in (apparently asleep) \\
\hline Awake & Lying relatively still with eyes open \\
\hline Unknown & Inactive but cannot tell whether awake \\
\hline Normal activity & $\begin{array}{l}\text { Animal neither lying down nor engaged in stereotypic behaviour; includes } \\
\text { eating, drinking and grooming }\end{array}$ \\
\hline \multicolumn{2}{|c|}{ Location of inactivity } \\
\hline In nest-box & At least half of the body inside the nest-box \\
\hline Other & Elsewhere in home cage \\
\hline Enriched cage & In enriched cage, tower or "tunnel" connecting the two cages \\
\hline \multicolumn{2}{|c|}{ Posture of mink while inactive } \\
\hline Belly up & Lying on back, with belly exposed \\
\hline Belly down & Lying on sternum \\
\hline Curled & Lying curled up \\
\hline
\end{tabular}

\subsection{Group 2}

This group consisted of 32 males and 32 females. Half of each sex was housed in E cages and half in NE cages from birth (in late April or early May). Live observations were conducted over 6 days in the second week of February, from 08:00 to 12:00 h each day, again before feeding, 
Appl. Anim. Behav. Sci. 144, pp. 136-146. (doi:10.1016/j.applanim.2013.01.00)

which occurred within an hour after the last scan. A modified form of scan sampling was used (see Dallaire et al., 2011 for details, and Bildsöe et al., 1990 and Svendsen et al., 2007a for validations), with a scan every 15 min (16 per day). The same ethogram was used as for Group 1. Mink were observed from at least two cage lengths away to minimize disturbance, and nothing was recorded until they had ceased looking at the observer. Two observers conducted additional scans on the same animals one afternoon, to confirm acceptable inter-observer reliability.

\subsection{Group 3}

In this group ( $\mathrm{N}=29), 13$ were initially housed in E cages (six male, seven female), and 16 initially housed in NE cages (eight of each sex). They had been placed in these housing treatments when aged approximately 3 months. These mink were also used in an experiment investigating boredom-like symptoms in mink (Meagher and Mason, 2012; also see Discussion).

\subsubsection{Effects of original housing}

Group 3 was observed for 7 days in April (Period 1; see Fig. 1 for timeline), using the same methods as for Group 2. Temperament was also assessed in the winter while the experimenter was still relatively unfamiliar to the mink, using "glove tests" to determine whether housing affected the prevalence of fearfulness: mink were classified as fearful, curious, aggressive or unresponsive based on responses to a handling glove placed against the cage (Meagher et al., 2011).

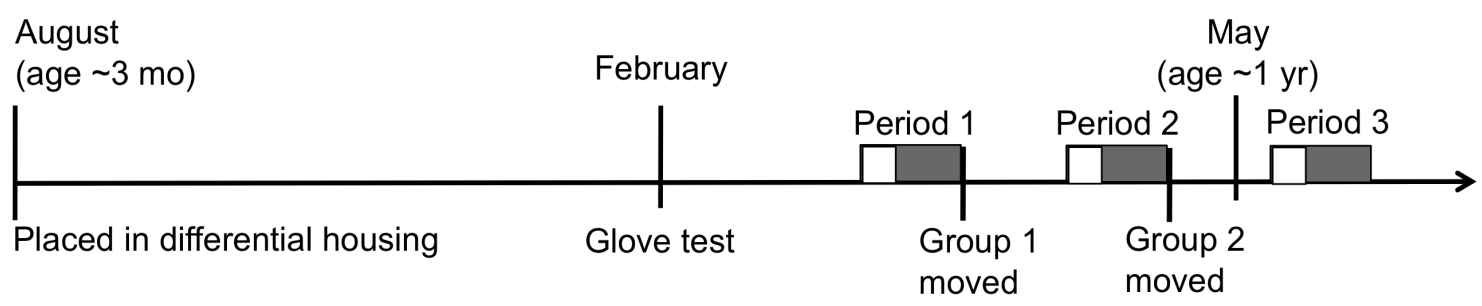

Fig. 1. Timeline of events for Group 3 (housing swap experiment). Boxes above the line indicate the three behavioural observation periods; white portions of the boxes indicate faecal collection days. 
Appl. Anim. Behav. Sci. 144, pp. 136-146. (doi:10.1016/j.applanim.2013.01.00)

\subsubsection{Housing change}

Following the first observation period, housing treatments were reversed: E mink were moved to NE cages, and vice versa. This was done in two stages, with half of the mink moved each time, to allow us to control for effects of time that were independent of the housing change. In each case, mink were given 1 week to habituate after being relocated, at which time another 6 to 7 days of scanning observations were conducted.

At the beginning of both observation periods (before and after the moves), faecal samples were collected to assess cortisol metabolite output (FCM). Samples were collected from beneath the cages every 24 hours, and pooled over 3 days to get an average for each individual. Cortisol metabolites were extracted from the homogenized samples using $80 \%$ methanol and analyzed using an 11ß-hydroxyaetiocholanolone enzyme immunoassay (Frigerio et al., 2004). The use of this FCM measure has been validated for mink, albeit females only (Malmkvist et al., 2011). These data, together with the change in stereotypic behaviour, were used to test whether losing enrichment induced stress, as well as to examine links between subtypes of inactivity and stress.

\subsection{Statistical analysis}

Analyses were conducted using JMP 9 (SAS Institute Inc., NC, USA 2009). To examine longterm housing effects, data from the three groups were pooled (using the data prior to the housing swap for Group 3). General linear models (GLMs) tested for housing effects on total inactivity and all subtypes of interest, controlling for sex, group, and their interactions with housing treatment. Where significant interactions were found, Tukey's Honestly Significant Difference (HSD) tests were used to identify groups differing at the level of $\alpha=0.05$. Interactions were removed from the models if $\mathrm{P}>0.25$. Assumptions of parametric tests were checked by inspection of residual plots (Grafen and Hails, 2002), and transformations applied where necessary. Logit transformations were applied to all dependent variables in this set of analyses to attain homogeneity of variance and normality.

For Group 3, several additional analyses were conducted. The response of each subtype of inactivity to the housing change was assessed in terms of the absolute increase or decrease in time spent on that behaviour compared to baseline levels in their original housing. One-way ttests, or Wilcoxon signed-rank tests in the case of non-normal data, were used to determine whether changes from baseline were significant within each treatment group; these analyses were 
Appl. Anim. Behav. Sci. 144, pp. 136-146. (doi:10.1016/j.applanim.2013.01.00)

split by sex if GLMs revealed interactions between sex and treatment. Housing effects on temperament in the glove test were also assessed using Chi-square tests. Changes in FCM after the move compared to before were analysed using GLMs controlling for sex, housing treatment, and whether the individual was in the first or second group moved (this group term being removed when it had a P>0.25). Changes in FCM between Periods 1 and 2 (see Fig. 1) for only those mink that had not yet been moved was analysed in the same way, to investigate seasonal effects. Finally, for any forms of inactivity reduced by enrichment, GLMs were used to determine whether they co-varied with temperament or FCM. Levels of these inactivity sub-types were also compared in Period 2 between individuals that had remained in NE housing and those that had just been moved from E to NE cages. All tests were two-tailed except in the analysis of FCM and stereotypic behaviour changes, in which it was expected that both FCM and stereotypic behaviour would increase when enrichment was removed.

\section{Results}

\subsection{Effects of current housing: pooled data}

Throughout, sex and group effects are not reported unless they interact with housing effects. For transformed data, back-transformed means are presented with transformed means following in square brackets. Results are summarized in Table 2.

Total inactivity did not differ between housing treatments $(\mathrm{P}>0.10)$. When inactivity was divided into awake or resting, time spent resting accounted for an average $92 \pm 12 \%$ of inactive time. In males, resting was lower in NE than E subjects, while females showed a non-significant difference in the opposite direction (sex*housing: $\mathrm{F}_{1,139}=4.91, \mathrm{P}=0.028$ ). Time spent inactive but awake, by contrast, was consistently higher in NE mink regardless of sex $(3.1 \% \mathrm{vs} .1 .7 \%$ of observations $[-3.44 \pm 0.15$ vs. $\left.-4.08 \pm 0.16] ; \mathrm{F}_{1,135}=9.66, \mathrm{P}=0.002\right)$. When inactivity was categorized by location, NE females spent more time inactive in their nest-boxes than E females did, while this effect was not significant in males (sex*housing $\mathrm{F}_{1,132}=20.1, \mathrm{P}<0.001$; Fig. 2). This housing effect also tended to differ between groups $\left(\mathrm{F}_{2,132}=2.70, \mathrm{P}=0.071\right)$, being significant at the $\alpha=0.05$ level in Groups 1 and 2 only (Tukey's HSD). Postures also differed between treatments: E mink spent more inactive time curled up than those in group $\mathrm{NE}\left(\mathrm{F}_{1,122}=10.9\right.$, $\mathrm{P}=0.013$ ), and less time lying belly down (i.e. on the sternum; $\mathrm{F}_{1,117}=10.0, \mathrm{P}=0.002$ ). Again, these differences varied among groups, being statistically significant only in Group 2 for both postures 
Appl. Anim. Behav. Sci. 144, pp. 136-146. (doi:10.1016/j.applanim.2013.01.00)

(curled: $\mathrm{F}_{2,122}=8.56, \mathrm{P}=0.003$; belly down: $\mathrm{F}_{2,117}=5.28, \mathrm{P}=0.006$ ). No significant housing effect on time spent lying belly up was detected $(\mathrm{P}>0.10)$. Posture data are presented in Table 3.

Table 2. Summary of effects of housing condition on inactivity and its subtypes.

\begin{tabular}{|c|c|c|c|c|c|c|}
\hline \multirow[b]{2}{*}{ Behaviour } & \multicolumn{2}{|c|}{ Original housing $(\mathrm{N}=140)^{1}$} & \multicolumn{4}{|c|}{ Housing change (Group 3 only) } \\
\hline & Main effect & *Group & $\begin{array}{c}\mathrm{E} \rightarrow \mathrm{NE}: \mathrm{M} \\
\quad(\mathrm{N}=6)\end{array}$ & $\begin{array}{c}\mathrm{E} \rightarrow \mathrm{NE}: \mathrm{F} \\
(\mathrm{N}=7)\end{array}$ & $\begin{array}{c}\mathrm{NE} \rightarrow \mathrm{E}: \mathrm{M} \\
(\mathrm{N}=8)\end{array}$ & $\begin{array}{c}\mathrm{NE} \rightarrow \mathrm{E}: \mathrm{F} \\
(\mathrm{N}=8)\end{array}$ \\
\hline Total inactivity & n.s. & n.s. & n.s. & n.s. & Decrease & Increase \\
\hline \multicolumn{7}{|l|}{ Type of inactivity } \\
\hline Resting & $\begin{array}{l}\mathrm{NE}<\mathrm{E} \\
\mathrm{M} \text { only }\end{array}$ & $?^{2}$ & n.s. & Decrease & Decrease & n.s. \\
\hline Lying awake & $\mathbf{N E}>\mathbf{E}$ & n.s. & Increase & Increase & Decrease & Decrease \\
\hline \multicolumn{7}{|c|}{ Location of inactivity } \\
\hline In nest-box & $\begin{array}{c}\text { NE }>\text { E } \\
\text { F only }\end{array}$ & $\begin{array}{c}\boldsymbol{N E}<\boldsymbol{E} \\
\text { Groups 1, } 2\end{array}$ & Increase & Increase & n.s. & n.s. \\
\hline Postural subtype & & & & & & \\
\hline $\begin{array}{l}\text { Proportion of } \\
\text { inactivity spent } \\
\text { belly up }\end{array}$ & n.s. & n.s. & n.s. & n.s. & Decrease & Decrease \\
\hline $\begin{array}{l}\text { Proportion of } \\
\text { inactivity spent } \\
\text { lying belly down }\end{array}$ & $\mathbf{N E}>\mathbf{E}$ & $\begin{array}{c}\text { NE }<\mathbf{E} \\
\text { Group } 2 \text { only }\end{array}$ & Increase & Increase & n.s. & n.s. \\
\hline $\begin{array}{l}\text { Proportion of } \\
\text { inactivity spent } \\
\text { curled }\end{array}$ & $\mathbf{N E}<\mathbf{E}$ & $\begin{array}{c}\text { NE }<\mathbf{E} \\
\text { Group } 2 \text { only }\end{array}$ & Decrease & Decrease & n.s. & n.s. \\
\hline
\end{tabular}

n.s. means no significant effect $(\mathrm{P}>0.10)$. Significant effects $(\mathrm{P}<0.05)$ are indicated in bold, and trends $(0.05<\mathrm{P}<0.10)$ in bold and italics. $\mathrm{M}$ stands for "male" and $\mathrm{F}$ for "female"; $\mathrm{E}$ means 'enriched' and NE means 'non-enriched'.

${ }^{1}$ For Group 3, these are housing effects before the treatment change.

2 There was a tendency for a housing* group effect at $\mathrm{P}=0.055$; however, no treatment differences within groups were significant according to Tukey's HSD. 


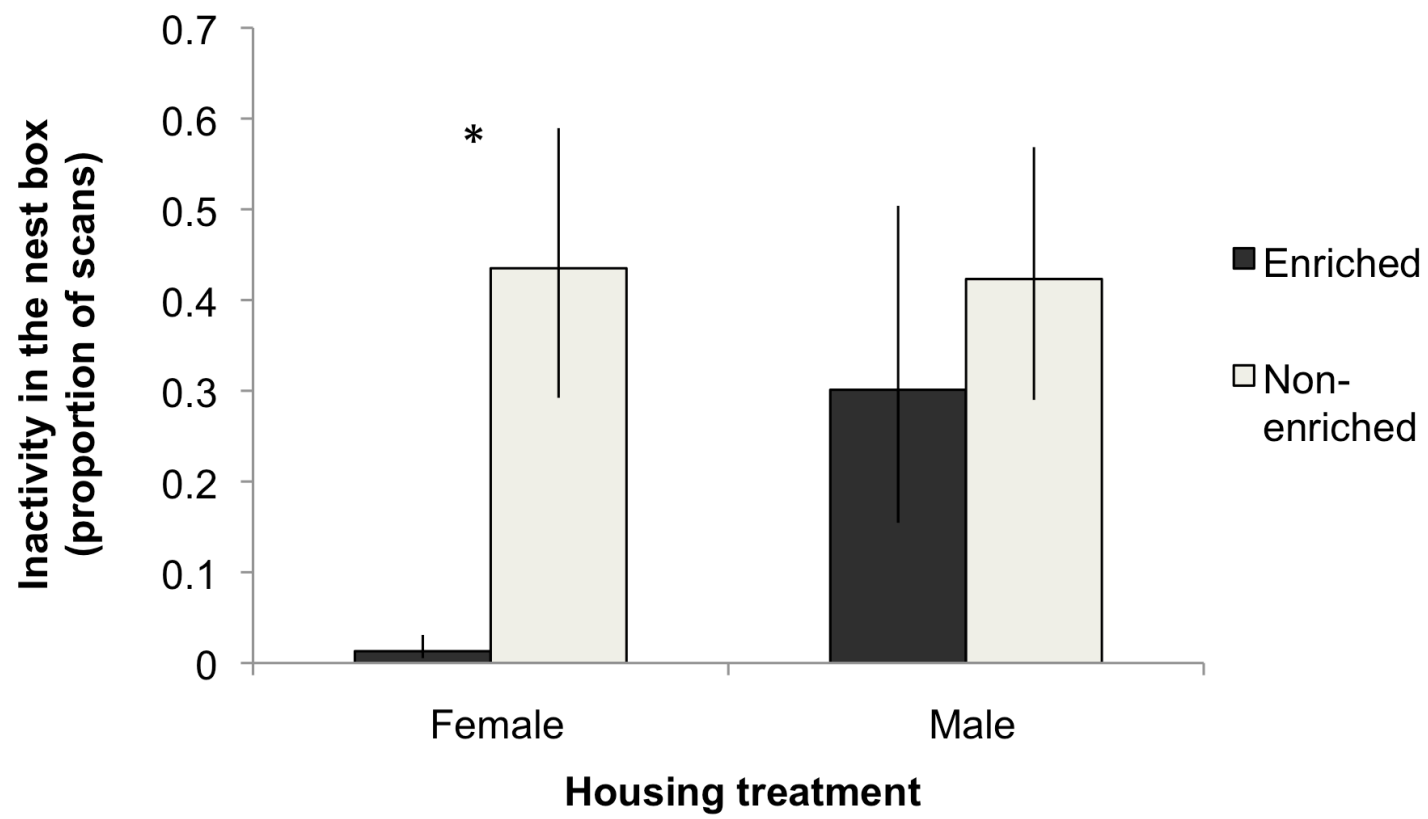

Fig. 2. Effect of housing on time spent inactive in the nest-box across all mink. Data are backtransformed least squares means with $95 \%$ confidence intervals. The asterisk indicates a change that was significant at the $\alpha=0.05$ level. $\mathrm{E}=$ enriched; $\mathrm{NE}=$ non-enriched. The logit-transformed means were: E females, $-4.32 \pm 0.45$; NE females, $-0.84 \pm 0.43$; E males, $-0.26 \pm 0.32$; and NE males, $-0.31 \pm 0.30$.

Table 3. Housing effects on posture (pooled analysis). Data presented are back-transformed least square means with logit-transformed means $\pm \mathrm{SE}$ in parentheses, split by group if there was a significant interaction.

\begin{tabular}{|c|c|c|}
\hline Posture & Enriched & Non-enriched \\
\hline $\begin{array}{l}\text { Proportion of inactivity } \\
\text { spent belly up }\end{array}$ & $0.007(-5.01 \pm 0.51)$ & $0.012(-4.45 \pm 0.50)$ \\
\hline Proportion of inactivity & Group 1: $0.002(-6.39 \pm 0.72)$ & Group 1: $0.003(-5.76 \pm 0.71)$ \\
\hline spent lying belly down & Group 2: $0.004(-5.45 \pm 0.59)$ & Group 2: $0.227(-1.23 \pm 0.65)^{*}$ \\
\hline \multirow{4}{*}{$\begin{array}{l}\text { Proportion of inactivity } \\
\text { spent curled }\end{array}$} & Group 3: $0.008(-4.81 \pm 0.84)$ & Group 3: $0.013(-4.34 \pm 0.76)$ \\
\hline & Group 1: $0.990(4.55 \pm 0.63)$ & Group 1: $0.985(4.18 \pm 0.61)$ \\
\hline & Group 2: $0.972(3.53 \pm 0.51)$ & Group 2: $0.321(-0.75 \pm 0.56)^{*}$ \\
\hline & Group 3: $0.955(3.06 \pm 0.72)$ & Group 3: $0.948(2.91 \pm 0.65)$ \\
\hline
\end{tabular}

\footnotetext{
* indicates a significant housing effect $(\alpha=0.05)$.
} 
Appl. Anim. Behav. Sci. 144, pp. 136-146. (doi:10.1016/j.applanim.2013.01.00)

\subsection{Effects of housing change on inactivity (Group 3 only)}

There was no overall change in inactivity with time for individuals not moved to new cages (Wilcoxon signed-rank test, $\mathrm{P}>0.10$ ). When mink were moved, there was an interaction between sex and direction of change for total inactivity $\left(\mathrm{F}_{1,25}=5.42, \mathrm{P}=0.028\right)$. Males moved from $\mathrm{NE}$ to $\mathrm{E}$ showed a significant decrease in inactivity by a mean of $15 \%( \pm 6 \%)$ of observations $(\mathrm{t}=-2.38$, d.f. $=7, \mathrm{P}=0.049$ ), while females tended to increase their inactivity when moved to $\mathrm{E}$ housing (by a mean of $8.7 \% \pm 4 \%$; $\mathrm{t}=2.05$, d.f. $=7, \mathrm{P}=0.08$ ). Neither sex, in contrast, showed significant changes in total inactivity when moved from $\mathrm{E}$ to $\mathrm{NE}(\mathrm{P}>0.10)$.

Similarly, for time spent resting, there was an interaction between sex and direction of housing change $\left(\mathrm{F}_{1,24}=4.93, \mathrm{P}=0.036\right)$. Again, males moved from $\mathrm{NE}$ to $\mathrm{E}$ showed a significant decrease $(S=-17.0$, d.f. $=7, P=0.016)$, with a median decrease of $47 \%$ of observations, while those moved from $\mathrm{E}$ to $\mathrm{NE}$ did not change significantly the amount of resting $(\mathrm{P}>0.10)$. However, in this case, females showed a significant change only if moved from $\mathrm{E}$ to $\mathrm{NE}$, in which case there was a median decrease of $13 \%$ of observations $(S=-13.0$, d.f. $=6, P=0.031$; NE-E: $P>0.10)$. Time spent lying awake increased significantly in mink moved to NE, regardless of sex $(\mathrm{S}=32.5$, d.f. $=12, \mathrm{P}=0.021$; Fig. 3), as did inactivity in the nest-box $(\mathrm{t}=2.73$, d.f. $=12, \mathrm{P}=0.018$; Fig. 4). In Period 2, however, neither lying awake nor inactivity in the nest-box was significantly higher in those just moved to NE than in those always housed in NE cages $(\mathrm{P}>0.10)$. Time spent lying awake also decreased in mink moved to $\mathrm{E}(\mathrm{S}=-53.5$, d.f. $=12, \mathrm{P}=0.004$; Fig. 3). Fig. 5 illustrates the changes in posture. The relative frequency of lying belly up tended to decrease in mink moved to $\mathrm{E}(\mathrm{t}=-1.93$, d.f. $=15, \mathrm{P}=0.07)$, but was unaffected by a move from $\mathrm{E}$ to $\mathrm{NE}(\mathrm{P}>0.10)$. Conversely, lying belly down tended to increase in mink moved to $\mathrm{NE}(\mathrm{S}=22.0$, d.f. $=15$, $\mathrm{P}=0.054)$ and remained unchanged in those moved to $\mathrm{E}(\mathrm{P}>0.10)$. Lying curled up was not significantly affected by being moved to $\mathrm{E}$, but tended to decrease if moved to $\mathrm{NE}(\mathrm{t}=-1.92$, d.f. $=$ $12, \mathrm{P}=0.079$ ). These findings are also summarized in Table 2. 


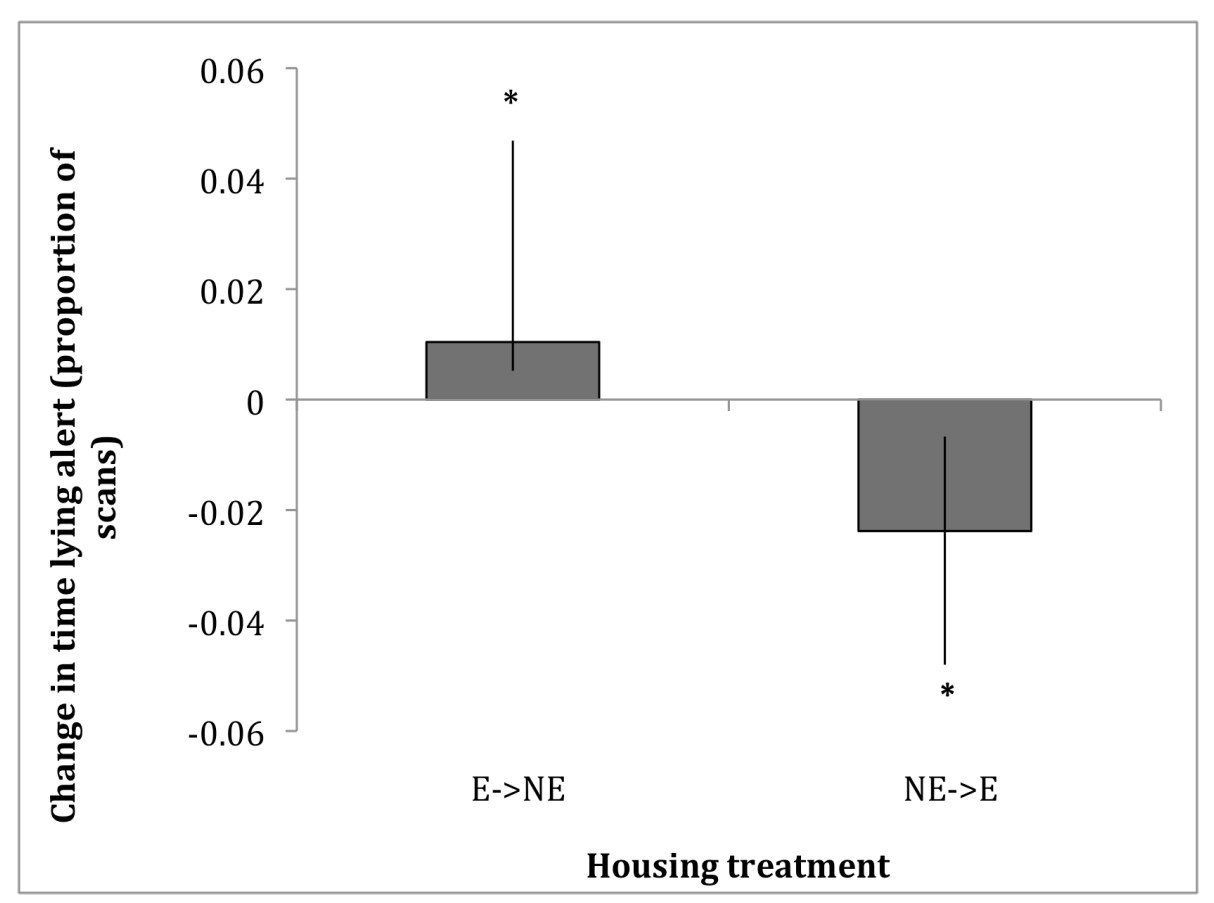

Fig. 3. Change in time spent lying awake after a change in housing treatment (Group 3 only). Data are medians, with error bars showing the interquartile range. The asterisk indicates a change that was significant at the $\alpha=0.05$ level. $E=$ enriched; $\mathrm{NE}=$ non-enriched.

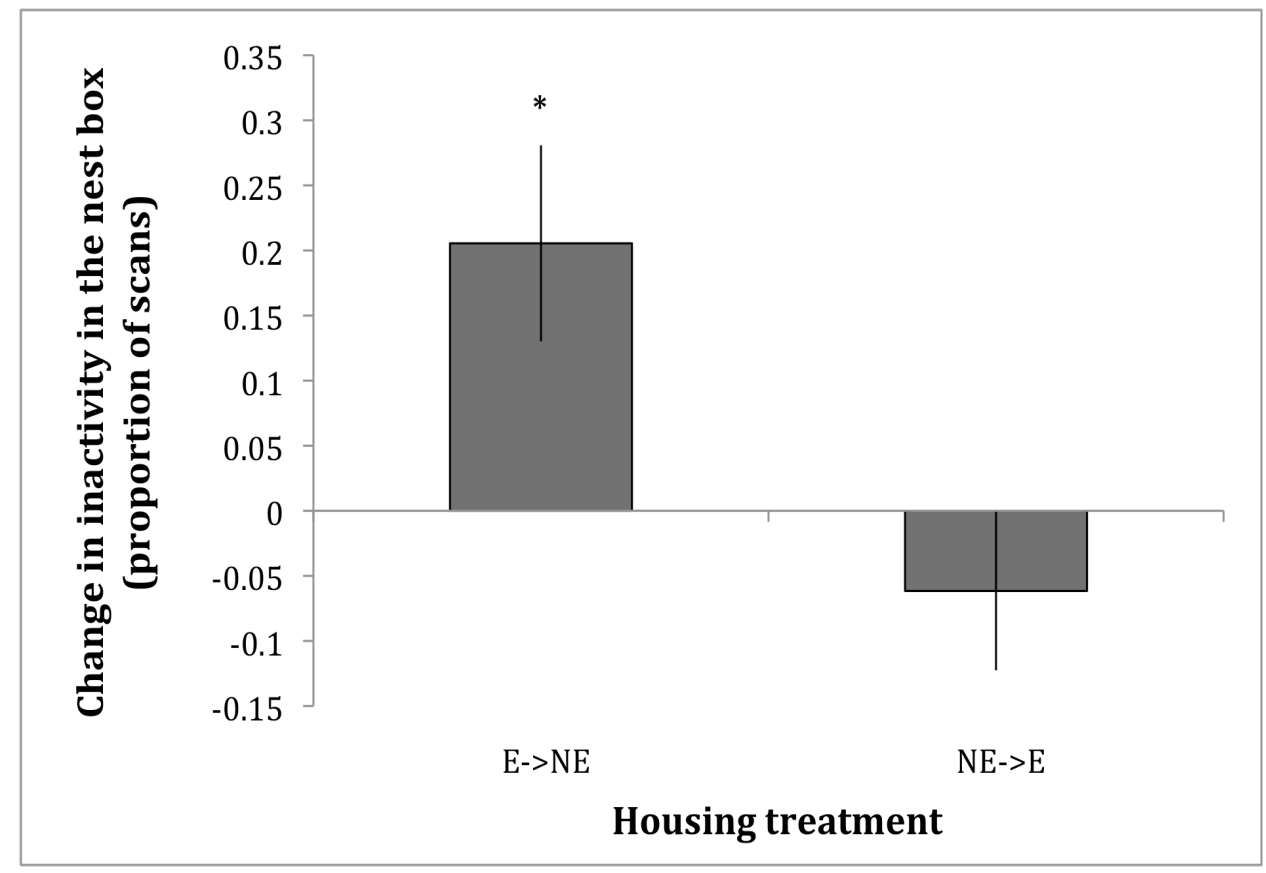

Fig. 4. Change in time spent inactive in the nest-box after a change in housing treatment (Group 3 only). Data are means \pm standard errors. The asterisk indicates a change that was significant at the $\alpha=0.05$ level. $E=$ enriched; $\mathrm{NE}=$ non-enriched. 


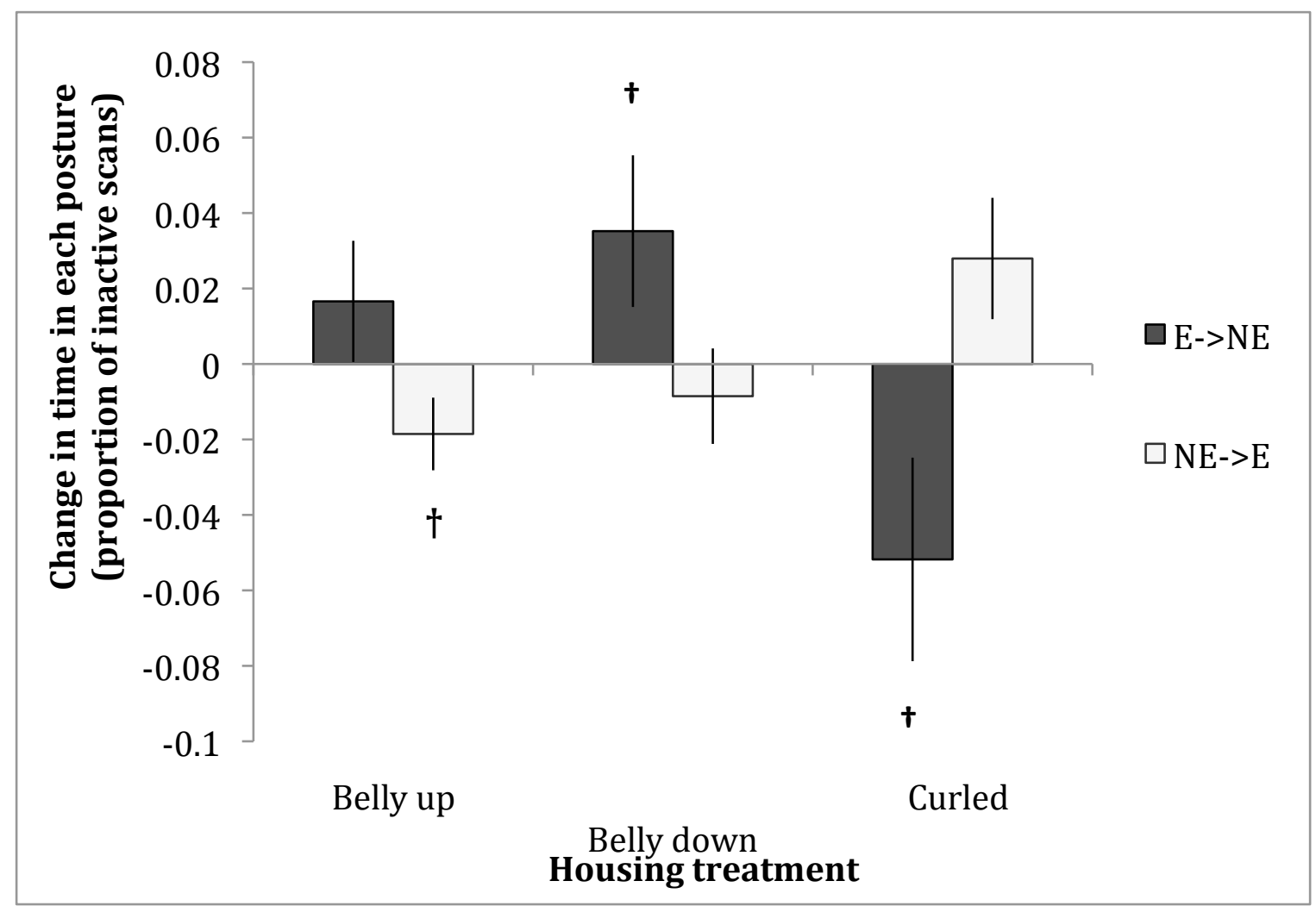

Fig. 5. Change in proportion of lying time spent in each posture after a change in housing treatment (Group 3 only). Data are means \pm standard errors. $\uparrow$ indicates an effect that differed from zero with $0.05<\mathrm{P}<0.10$. $\mathrm{E}=$ enriched; $\mathrm{NE}=$ non-enriched.

\subsection{Effects of housing on welfare indicators: Group 3 only}

In their original housing conditions, the number of $\mathrm{E}$ and $\mathrm{NE}$ mink categorized as fearful in glove tests did not differ (31\% in both groups; $\mathrm{P}>0.10)$. However, E mink had lower levels of FCM $\left(\mathrm{F}_{1,25}=4.67, \mathrm{P}=0.040\right.$; least squares means: $160 \mathrm{ng} / \mathrm{g}$ vs. $234 \mathrm{ng} / \mathrm{g}$ [log-transformed: $5.08 \pm 0.13$ vs. $5.46 \pm 0.12])$. Stereotypic behaviour was highest in NE females, but was not affected by housing in males (housing* $\operatorname{sex}_{1,25}=9.91, \mathrm{P}=0.004$; least squares mean proportions of scans: 0.006 for E females vs. 0.083 for NE females [logit: $-5.10 \pm 0.42$ vs. $-2.41 \pm 0.29]$ ).

FCM changed over time, independent of the housing change: FCM tended to decrease overall between observation periods in the group that had not yet been moved (mean concentration difference: $72.9 \mathrm{ng} / \mathrm{g}$; $\mathrm{t}=-2.04$, d.f. $=13, \mathrm{P}=0.062$ ). However, although there was similarly a decrease in all groups after they were moved, this decrease was larger in those moved to $\mathrm{E}$ housing (36 ng/g vs. $106 \mathrm{ng} / \mathrm{g}$ for mink moved to $\mathrm{NE} ; \mathrm{F}_{1,23}=3.49$, one-tailed $\mathrm{P}=0.037$ ). The change in locomotor stereotypy differed between sexes (direction of housing change*sex 
Appl. Anim. Behav. Sci. 144, pp. 136-146. (doi:10.1016/j.applanim.2013.01.00)

$\left.\mathrm{F}_{1,25}=9.43, \mathrm{P}=0.005\right)$. One-tailed Wilcoxon signed-rank tests revealed a non-significant trend for an increase in females moved to NE (median change: $0.6 \%$ of observations; $S=5.00$, d.f. $=6$, $\mathrm{P}=0.063$ ), and significant decrease in females moved to $\mathrm{E}$ (median change: $5.8 \%$ of observations; $\mathrm{S}=-17.0$, d.f. $=7, \mathrm{P}=0.008$ ). Male stereotypy, in contrast, did not alter when housing was changed in either direction $(\mathrm{P}>0.10)$.

\subsection{Relationships between inactivity subtypes of interest and stress/fear (Group 3 only)}

The relationships between stress or fearfulness (assessed via FCM and responses in glove tests) and the subtypes of inactivity that were sometimes decreased by enrichment (lying awake, inactivity in the nest-box, and lying belly down) were investigated. Time spent lying awake in the pre-move period did not correlate with either FCM or temperament in the glove test (both $\mathrm{P}>0.10$ ). There was also no relationship between the change in time lying awake after being moved and the change in FCM $(\mathrm{P}>0.10)$. For time inactive in the nest-box, there was no significant relationship with FCM before the move $(\mathrm{P}>0.10)$. There was a trend for a relationship with temperament, which interacted with sex $\left(\mathrm{F}_{2,20}=3.40, \mathrm{P}=0.054\right)$ : fearful males spent the highest proportion of time inactive in their nest-boxes (least squares mean: $0.64 \pm 0.12$ ) and curious females spent the least (least squares mean: $0.02 \pm 0.11$ ). However, Tukey's HSD tests did not show any significant differences between fearful and curious mink within either sex $(\mathrm{P}>0.05)$. Similarly, there was an interaction with sex in the analysis of change in inactivity in the nest-box versus change in $\mathrm{FCM}\left(\mathrm{F}_{1,22}=6.41, \mathrm{P}=0.019\right)$. The relationship with FCM did not attain statistical significance in either sex when the analysis was split $(\mathrm{P}>0.10)$; by inspection, however, it appeared that for females, large decreases in FCM corresponded with large decreases in inactivity in the nest-box. Proportion of inactive time spent belly down did not correlate with FCM before the move $(\mathrm{P}>0.10)$. For temperament, there was an interaction with treatment $\left(\mathrm{F}_{2,17}=3.53, \mathrm{P}=0.047\right)$ : in $\mathrm{E}$, fearful individuals spent the highest proportion of their time belly down (least square means: 0.027 and 0.006 [logit: $-3.59 \pm 0.69$ and $-5.10 \pm 0.60$ ] for fearful and confident, respectively), while in NE, they spent the least (0.006 and $0.027[-5.12 \pm 0.60$ and $3.57 \pm 0.58]$ for fearful and confident, respectively). Again, however, no difference was significant according to Tukey's HSD. Unexpectedly, there was a negative relationship between change in the relative frequency of this belly down posture after the move and change in FCM ( $\log$-transformed; $\beta=-0.004, \mathrm{~F}_{1,23}=10.5, \mathrm{P}=0.004$ ), i.e. the larger the decrease in $\mathrm{FCM}$, the 
Appl. Anim. Behav. Sci. 144, pp. 136-146. (doi:10.1016/j.applanim.2013.01.00)

smaller the decrease in proportion of lying time spent belly down; in some cases, the proclivity for lying belly down even increased when FCM decreased.

\section{Discussion}

Our primary hypotheses were broadly that impoverished housing should reduce resting, but increase other specific types of inactivity, such as that occurring in the nest-box. Testing these hypotheses rested on the assumption that, just as in previous studies, environmental enrichment would benefit our minks' welfare. Data from Group 3 supported this assumption: E mink excreted lower levels of FCM, and female E mink were less stereotypic than female NE mink. E mink were no less likely to be fearful, but this may reflect the reduced power of tests using qualitative data, or instead indicate that the welfare problems induced by non-enriched housing are of a type other than fear (e.g. frustration or boredom: an issue returned to below). For Group 3 animals, we reversed their housing conditions to further test these hypotheses, predicting that any housing effects on certain forms of inactivity would be strongest in mink with prior experiences with the other housing type (Hypothesis 2). Moving mink between housing types further confirmed the welfare benefits of E housing: the time-dependent FCM decline across all subjects was greatest in mink moved from NE to E housing, and the same move reduced female stereotypic behaviour. However, it was not evident that enrichment loss was worse for mink welfare than lifelong privation, as had been predicted (Hypothesis 2): no variables were affected by enrichment removal that had not been seen as simple effects of long-term housing in at least one sex or group. In practice, the main experimental benefit of the housing swap was thus to maximise statistical power, by exposing all subjects in Group 3 (which had a small N) to both E and NE housing.

In terms of total overall inactivity, long-term housing had no significant effects. Being given enrichment later in life did decrease inactivity in Group 3's males, as might be expected from the increased behavioural opportunities afforded by the enriched cages and the predicted decrease in stress-related inactivity subtypes. However, additional data from Group 2 alone collected in another experiment indicated that long-term enrichment actually increased inactivity in males (Díez-León et al., in prep.). These contradictory effects were unsurprising, given previous research (see Introduction) and the anticipated heterogeneity of this behaviour category. 
Appl. Anim. Behav. Sci. 144, pp. 136-146. (doi:10.1016/j.applanim.2013.01.00)

Our expectation was that studying different subtypes of inactivity - subtypes based on apparent function, location, and posture - should produce less variable, more predictable, results. Our specific predictions were that non-enriched cages would: decrease time spent sleeping but increase time spent lying awake (Hypothesis 1a); increase time spent inactive in a location that might be perceived as safe, namely the nest-box, while decreasing inactivity in exposed areas of the cage (Hypothesis 1b); and also influence the type of postures displayed (Hypothesis 1c). All three were supported, but Hypotheses $1 \mathrm{a}$ and $1 \mathrm{~b}$ most strongly, as follows.

In partial support of Hypothesis 1a, resting or sleeping was decreased by NE housing in males (but not females), and decreased by enrichment removal in females. Puzzlingly, however, it decreased in males moved from NE to E housing. More convincing support of Hypothesis 1a was the finding that lying awake was reliably increased by NE cages. Across all subjects, this behaviour occurred less in enriched than non-enriched mink, and correspondingly, in Group 3 it decreased in mink moved from NE to E housing, while increasing in mink moved from $\mathrm{E}$ to NE. Several authors have documented similar effects in other species, with both pigs and mice spending more time inactive but awake when in impoverished versus complex, enriched living conditions (e.g. Bolhuis et al., 2006; Tilly et al., 2010). In support of Hypothesis 1b, categorizing inactivity by location also seemed to hold promise for assessing mink welfare. Inactivity in the nest-box was rather consistently reduced by enrichment, as predicted: it was decreased in females overall, and in Group 3 it was increased by enrichment removal, while decreased by providing enrichment to the formerly NE subjects. Relationships between these two forms of inactivity and other welfare indicators are discussed below.

Hypothesis 1c concerned posture. These analyses were primarily exploratory, and directional predictions were not made. The broad hypothesis was supported, in that housing type did affect postures adopted while inactive. In Group 2, E animals were more likely than NE mink to lie curled up. In Group 3, this type of lying tended to decrease in mink from which enrichments were removed. Conversely, E mink in Group 2 were less likely than NE mink to lie belly down, and this posture tended to increase in mink from which enrichments were removed. Analyses did not, in contrast, detect any treatment effects on lying belly up. This may simply be due to low statistical power, since it was a relatively rare posture. However, the trend for a decrease in time lying belly up when moved from NE to E conditions suggests that, contrary to 
Appl. Anim. Behav. Sci. 144, pp. 136-146. (doi:10.1016/j.applanim.2013.01.00)

expectations, it may not actually reflect greater relaxation. These postures' complex relationships with other welfare indicators are discussed below.

Our third hypothesis was that subtypes of inactivity that were elevated by NE housing would correlate with fear and stress as assessed via temperament and glucocorticoid levels. This was broadly confirmed for inactivity in the nest-box: fearful males spent the most time inactive in their nest-boxes; curious females spent the least time there; and for females, changes in this behaviour also co-varied with changes in FCM after the move between treatments, with a large decrease in FCM corresponding to a large decrease in inactivity in the nest-box. This suggests that at least some nest-box use may be a form of hiding. In contrast, lying awake, the other form of inactivity consistently higher in NE cages, was unrelated to FCM or glove test indicators of fear or stress. Thus suggests that lying awake is not an anxiety-driven response, such as vigilance, in mink. It is therefore possible that it reflects other negative affective states induced by the lack of enrichment, such as frustration, depression, apathy or boredom, as discussed below. Finally, although lying belly-down was more common in non-enriched conditions, it was not linked to negative states by these other welfare indicators (lying belly-down tended to be associated with greater fearfulness in enriched conditions, but the relationship was not statistically significant, and belly-down postures correlated negatively with FCM changes during the housing swap). Thus, it is unclear whether an increased preference for lying belly-down indicates poor welfare.

For mink, the differential effects of stress-reducing enrichment on different subtypes of inactivity help to identify which subtypes hold most promise as valid welfare indicators for this species. Two subtypes of inactivity were most closely linked with the poor welfare induced by impoverished housing. One was remaining inactive in the nest-box, which may reflect chronic fear or stress. Corroborating tests of this hypothesis could include offering mink a choice of nestboxes that differ in their degree of visual enclosure, distance from humans and amount of bedding. If the increased nest-box use in impoverished cages is linked to fear, these mink would be expected to prefer enclosed nest-boxes far from humans, and this preference should co-vary with responses to temperament tests; by contrast, mink using the nest-box primarily as a comfortable resting place should prefer those with more bedding even if the walls are transparent. Future work should also seek to investigate which aspects of nest-box use reflect hiding, since most of the animals' resting occurred here too and it seems likely that much nest-box use is benign (perhaps that accompanied by true sleep, which could be assessed using 
Appl. Anim. Behav. Sci. 144, pp. 136-146. (doi:10.1016/j.applanim.2013.01.00)

electroencephalography [EEG]), with only a fraction reflecting fear. The second subtype linked to poor welfare was remaining inactive but awake. Since fear and stress were not implicated, boredom, apathy and depression remained as candidate affective states that might underlie this subtype. All three have previously been hypothesized to exist in captive animals (e.g. apathy: Bolhuis et al., 2006; depression: Carlstead, 1996; boredom: van Putten, 1980; Wemelsfelder, 1990; Wood-Gush and Beilharz, 1983) because they are linked in humans to problems that are likely present in many captive environments: low levels of stimulation or chronic stress (see e.g. Berlyne, 1960; Henn and Vollmayr, 2005). We have thus already conducted follow-up research using the mink from Group 3 of this study to investigate these alternative hypotheses. The results of this study (Meagher and Mason, 2012) suggested that lying awake definitely does not reflect apathy, but may reflect a boredom-like state in mink.

\section{Conclusions}

Our results help explain why impoverished housing has rather inconsistent effects on overall levels of inactivity across studies. This housing may reduce resting or sleeping, but conversely it may increase subtypes of inactivity associated with negative affective states such as boredom, apathy or fear. The balance between these contrasting effects will likely depend on the species and the types of enrichment given to the comparison group. Our data also show that different subtypes of inactivity - identified by location, posture and/or apparent level of arousal - have quite different welfare implications for mink, being differentially associated with housing conditions, elevated FCM output or fearful temperaments. This suggests that recording specific subtypes of inactivity is considerably more informative for welfare than recording overall inactivity. Future studies of mink welfare, and likely of welfare in other species as well, should thus record different forms of inactivity separately rather than using it as a catch-all category.

\section{Acknowledgements}

Many thanks to William Sears for his statistical advice, and to the Michigan State University research farm for allowing us to use their facilities. RKM was supported by an NSERC CGS. The research was funded by an NSERC Discovery grant to GJM. 
Appl. Anim. Behav. Sci. 144, pp. 136-146. (doi:10.1016/j.applanim.2013.01.00)

\section{References}

Abou-Ismail, U.A., Mahboub, H.D., 2011. The effects of enriching laboratory cages using various physical structures on multiple measures of welfare in singly-housed rats. Lab. Anim. 45, 145-153.

Aristakesyan, E.A., 2009. Evolutionary aspects of interaction of sleep and stress: Phylo- and ontogenetic approach. J. Evol. Biochem. Physiol. 45, 724-739.

Axelsson, H.M.K., Alden, E., Lidfors, L., 2009. Behaviour in female mink housed in enriched standard cages during winter. Appl. Anim. Behav. Sci. 121, 222-229.

Baker, K., 2004. Benefits of positive human interaction for socially housed chimpanzees. Anim. Welf. 13, 239-245.

Berlyne, D.E., 1960. Conflict, Arousal, and Curiosity. McGraw-Hill, New York.

Bildsøe, M., Heller, K.E., Jeppesen, L.L., 1990. Stereotypies in female ranch mink: seasonal and diurnal variation. Scientifur 14, 243-248.

Bildsøe, M., Heller, K.E., Jeppesen, L.L., 1991. Effects of immobility stress and food restriction on stereotypies in low and high stereotyping female ranch mink. Behav. Processes 25, 179-189.

Bolhuis, J.E., Schouten, W.G.P., Schrama, J.W., Wiegant, V.M., 2006. Effects of rearing and housing environment on behaviour and performance of pigs with different coping characteristics. Appl. Anim. Behav. Sci. 101, 68-85.

Campbell, D.L.M., Dallaire, J.A., Mason, G.J., 2013. Environmentally enriched rearing environments reduce repetitive perseveration in caged mink, but increase spontaneous alternation. Behav. Brain Res. 239, 177-187.

Carlstead, K., 1996. Effects of captivity on the behavior of wild mammals, in: Kleiman, D.G., Allen, M.E., Thompson, K.V., Lumpkin, S. (Eds.), Wild Mammals in Captivity. University of Chicago Press, Chicago, pp. 317-333.

Carlstead, K., Brown, J.L., Seidensticker, J., 1993. Behavior and adrenocortical responses to environmental changes in leopard cats (Felis bengalensis). Zoo Biol. 12, 321-331.

Crockett, C.M., Bowers, C.L., Shimoji, M., Leu, M., Bowden, D.M., Sackett, G.P., 1995.

Behavioral-Responses of Longtailed Macaques to Different Cage Sizes and Common Laboratory Experiences. J. Comp. Psychol. 109, 368-383.

Dallaire, J.A., Meagher, R.K., Díez-León, M., Garner, J.P., Mason, G.J., 2011. Recurrent perseveration correlates with abnormal repetitive locomotion in adult mink but is not reduced by environmental enrichment. Behav. Brain Res. 224, 213-222.

Dallaire, J.A., Meagher, R.K., Mason, G.J., 2012. Individual differences in stereotypic behaviour predict individual differences in the nature and degree of enrichment use in caged American mink. Appl. Anim. Behav. Sci. 142, 98-108.

Dalm, S., de Visser, L., Spruijt, B.M., Oitzl, M.S., 2009. Repeated rat exposure inhibits the circadian activity patterns of C57BL/6J mice in the home cage. Behav. Brain Res. 196, 84-92. Díez-León, M., Mason, G., 2010. Male mink (Mustela vison) from enriched cages are more successful as mates. Proc. $44^{\text {th }}$ Congress ISAE, 96.

Dishman, D.L., Thomson, D.M., Karnovsky, N.J., 2009. Does simple feeding enrichment raise activity levels of captive ring-tailed lemurs (Lemur catta)? Appl. Anim. Behav. Sci. 116, 88-95. Fraser, D., 1975. The effect of straw on the behaviour of sows in tether stalls. Anim. Prod. 21, 59-68.

Frigerio, D., Dittami, J., Möstl, E., Kotrschal, K., 2004. Excreted corticosterone metabolites covary with ambient temperature and air pressure in male Greylag geese (Anser anser). Gen. Comp. Endocrinol. 137, 29-36. 
Appl. Anim. Behav. Sci. 144, pp. 136-146. (doi:10.1016/j.applanim.2013.01.00)

Grafen, A., Hails, R., 2002. Modern Statistics for the Life Sciences. Oxford University Press, Inc., New York.

Gunn, D., Morton, D.B., 1995. Inventory of the Behavior of New-Zealand White-Rabbits in Laboratory Cages. Appl. Anim. Behav. Sci. 45, 277-292.

Hansen, S.W., Jeppesen, L.L., 2006. Temperament, stereotypies and anticipatory behaviour as measures of welfare in mink. Appl. Anim. Behav. Sci. 99, 172-182.

Hansen, S.W., Malmkvist, J., Palme, R., Damgaard, B.M., 2007. Do double cages and access to occupational materials improve the welfare of farmed mink? Anim. Welf. 16, 63-76.

Henn, F.A., Vollmayr, B., 2005. Stress models of depression: forming genetically vulnerable strains. Neurosci. Biobehav. Rev. 29, 799-804.

Koistinen, T., Turunen, A., Kiviniemi, V., Ahola, L., Mononen, J., 2009. Bones as enrichment for farmed blue foxes (Vulpes lagopus): Interaction with the bones and preference for a cage with the bones. Appl. Anim. Behav. Sci. 120, 108-116.

Langford, F.M., Cockram, M.S., 2010. Is sleep in animals affected by prior waking experiences?

Anim. Welf. 19, 215-222.

Latham, N., Mason, G., 2010. Frustration and perseveration in stereotypic captive animals: Is a taste of enrichment worse than none at all? Behav. Brain Res. 211, 96-104.

Malmkvist, J., Jeppesen, L.L., Palme, R., 2011. Stress and stereotypic behaviour in mink (Mustela vison): A focus on adrenocortical activity. Stress 14, 312-323.

Mason, G.J., 1992. Individual variation in the stereotypies of caged mink. PhD Thesis, University of Cambridge, UK.

Mason, G.J., Cooper, J., Clarebrough, C., 2001. Frustrations of fur-farmed mink. Nature 410, $35-$ 36.

Meagher, R.K., Mason, G.J., 2012. Environmental enrichment reduces signs of boredom in caged mink. PLOS One 7, e49180.

Meagher, R., Bechard, A., Palme, R., Díez-León, M., Hunter, D.B., Mason, G., 2012. Decreased litter size in inactive female mink (Neovison vison): Mediating variables and implications for overall productivity. Can. J. Anim. Sci. 92, 131-141.

Meagher, R.K., Duncan, I., Bechard, A., Mason, G.J., 2011. Who's afraid of the big bad glove?

Testing for fear and its correlates in mink. Appl. Anim. Behav. Sci. 133, 254-264.

Nimon, A.J., Broom, D.M., 1999. The welfare of farmed mink (Mustela vison) in relation to housing and management: A review. Anim. Welf. 8, 205-228.

Petrů, M., Spinka, M., Charvatova, V., Lhota, S., 2009. Revisiting Play Elements and SelfHandicapping in Play: A Comparative Ethogram of Five Old World Monkey Species. J. Comp.

Psych. 123, 250-263.

Rasa, O.A.E., 1989. Behavioral Parameters of Vigilance in the Dwarf Mongoose - Social Acquisition of a Sex-Biased Role. Behaviour 110, 125-145.

Rochlitz, I., Podberscek, A.L., Broom, D.M., 1998. Welfare of cats in a quarantine cattery. Vet. Rec. 143, 35-39.

Rozek, J.C., Danner, L.M., Stucky, P.A., Millam, J.R., 2010. Over-sized pellets naturalize foraging time of captive Orange-winged Amazon parrots (Amazona amazonica). Appl. Anim. Behav. Sci. 125, 80-87.

Soriano, A.I., Ensenyat, C., Serrat, S., Mate, C., 2006. Introducing a semi-naturalistic exhibit as structural enrichment for two brown bears (Ursus arctos). Does this ensure their captive wellbeing? J. Appl. Anim. Welf. Sci. 9, 299-314.

Svendsen, P.M., Hansen, S.W., Jeppesen, L.L., 2007a. Direct scan sampling reliably reflects video recorded differences in stereotypy in selected lines of mink. Scientifur 31, 19-25. 
Svendsen, P.M., Hansen, B.K., Malmkvist, J., Hansen, S.W., Palme, R., Jeppesen, L.L., $2007 b$. Selection against stereotypic behaviour may have contradictory consequences for the welfare of farm mink (Mustela vison). Appl. Anim. Behav. Sci. 107, 110-119.

Tembrock, G., 1979. Choice of Side of Resting Position in Vulpes-Vulpes (L). Behav. Processes 4, 129-144.

Tilly, S.C., Dallaire, J., Mason, G.J., 2010. Middle-aged mice with enrichment-resistant stereotypic behaviour show reduced motivation for enrichment. Anim. Behav. 80, 363-373. Tromp, J., Lahaije, M., Nijssen, A., 1990. Sleep Postures and Power Spectrum Analysis of the EEG of the Rat. Behav. Processes 22, 151-155.

Tuyttens, F.A.M., Wouters, F., Struelens, E., Sonck, B., Duchateau, L., 2008. Synthetic lying mats may improve lying comfort of gestating sows. Appl. Anim. Behav. Sci. 114, 76-85. van Putten, G., 180. Objective observations on the behaviour of fattening pigs. Anim. Regul. Stud. 3, 105-118.

Vestergaard, K. 1984. An evaluation of ethological criteria and methods in the assessment of wellbeing in sows. Ann. Rech. Vét. 15, 227-235.

Vinke, C.M., van Leeuwen, J., Spruijt, B., 2005. Juvenile farmed mink (Mustela vison) with additional access to swimming water play more frequently than animals housed with a cylinder and platform, but without swimming water. Anim. Welf. 14, 53-60.

Wemelsfelder, F., 1990. Boredom and Laboratory Animal Welfare, in: Rollin, B.E., Kesel, M.L. (Eds.), The Experimental Animal in Biomedical Research. CRC-Press, Boca Raton, Florida, pp. 243-272.

Wielebnowski, N.C., Fletchall, N., Carlstead, K., Busso, J.M., Brown, J.L., 2002. Noninvasive assessment of adrenal activity associated with husbandry and behavioral factors in the North American clouded leopard population. Zoo Biol. 21, 77-98.

Wood-Gush, D.G.M., Beilharz, R.G., 1983. The enrichment of a bare environment for animals in confined conditions. Appl. Anim. Ethol. 10, 209-217.

Würbel, H., Freire, R., Nicol, C.J., 1998. Prevention of stereotypic wire-gnawing in laboratory mice: Effects on behaviour and implications for stereotypy as a coping response. Behav. Proc 